\title{
Retrospective Analysis of the Factors Affecting Growth Parameters in Turkish Children With Systemic Lupus Erythematosus
}

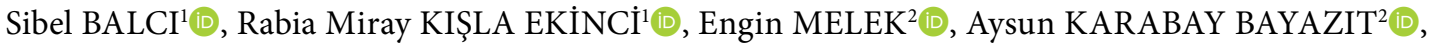 \\ Dilek DOĞRUEL ${ }^{3}$ (D), Derya UFUK ALTINTAŞiD, Mustafa YILMAZ ${ }^{1}$ \\ ${ }^{1}$ Department of Pediatrics, Division of Pediatric Rheumatology, Çukurova University School of Medicine, Adana, Turkey \\ ${ }^{2}$ Department of Pediatrics, Division of Pediatric Nephrology, Çukurova University School of Medicine, Adana, Turkey \\ ${ }^{3}$ Department of Pediatrics, Division of Pediatric Allergy and Immunology, Çukurova University School of Medicine, Adana, Turkey
}

\begin{abstract}
Objectives: This study aims to investigate the growth parameters in Turkish children with systemic lupus erythematosus (SLE) and to compare these growth parameters according to the presence or absence of cyclophosphamide, rituximab treatment, cumulative corticosteroid dose, proliferative nephritis, and the last visit disease activity and damage index.

Patients and methods: Medical data, growth parameters including z-scores for weight, height, and body mass index and parent-adjusted height z-scores of 45 juvenile SLE (jSLE) patients ( 5 males, 40 females; mean age $12.3 \pm 3.2$ years; range 7.1 to 18 years) were retrospectively evaluated. Growth parameters were calculated by anthropometric references in Turkish children. The disease activity was assessed by the SLE Disease Activity Index 2000 (SLEDAI-2K). The disease outcome was measured by the Pediatric version of Systemic Lupus International Collaborating Clinics/American College of Rheumatology Damage Index.

Results: The median diagnostic delay was two months (range, 0-36 months). The median follow-up duration was 3.21 years (range, $0.63-9.48$ years). Mean height z-score was significantly lower at last visit than at the time of diagnosis. The growth parameters did not differ according to age at disease onset, diagnostic delay, presence of proliferative nephritis, having cyclophosphamide and rituximab treatment and the last visit (SLEDAI-2K) scores. The median duration of corticosteroid treatment was 3.2 years (range, 0.6-9.4 years) and the median cumulative corticosteroid dosage was $13.9 \mathrm{~g}$ (range, $1.9-58 \mathrm{~g}$ ) of methylprednisolone. The mean height $\mathrm{z}$-score at last visit was significantly lower in those who received at least $10 \mathrm{~g}$ of cumulative dose of corticosteroid. The last visit mean parent-adjusted height z-scores did not differ significantly regarding the cumulative corticosteroid dose. Conclusion: The last visit height and parent-adjusted height $\mathrm{z}$-scores of jSLE patients were significantly lower. The patients treated with at least $10 \mathrm{~g}$ of cumulative dose of corticosteroids had lower mean height z-score.

Keywords: Children, corticosteroid, damage, growth, juvenile systemic lupus erythematosus.
\end{abstract}

Systemic lupus erythematosus (SLE) is an autoimmune, inflammatory disease presented by various clinical manifestations and has an unpredictable course. Children represent nearly $15-20 \%$ of SLE patients. ${ }^{1}$ Disease incidence, severity, organ involvement, mortality and morbidity rate of juvenile SLE (jSLE) vary among ethnic groups. ${ }^{2,3}$ The course of jSLE is more severe than adult-onset SLE and jSLE requires more intensive treatment to prevent higher rates of mortality. ${ }^{4}$ However, the mortality of jSLE patients has considerably decreased over the past decades, presumably in response to early diagnosis and better treatment modalities. Therefore, children with jSLE are now living longer with this chronic disease and enter their adult lives with several comorbidities. As a result of increased lifespan, children with jSLE encounter a considerable

Received: April 26, 2019 Accepted: October 13, 2019 Published online: January 08, 2020

Correspondence: Sibel Balcı, MD. Çukurova Üniversitesi Tıp Fakültesi Çocuk Sağlığı ve Hastalıkları Anabilim Dalı, Çocuk Romatolojisi Bilim Dalı, 01380 Sarıçam, Adana, Türkiye. Tel: +90 507 - 5339301 e-mail: drsibelbalci@hotmail.com

Balcı S, Kışla Ekinci RM, Melek E, Karabay Bayazıt A, Doğruel D, Ufuk Altıntaş D, et al. Retrospective Analysis of the Factors Affecting Growth Parameters in Turkish Children With Systemic Lupus Erythematosus. Arch Rheumatol 2020;35(3):357-365. 
amount of morbidity caused by sequelae of disease activity, side effects of medications, and comorbid conditions. ${ }^{5}$

Growth is an important indicator of well-being in children. Chronic inflammatory diseases such as jSLE may cause important changes in growth parameters and may ultimately lead to diminished height. As a result of prescribed medications, obesity may also occur. The Pediatric version of Systemic Lupus International Collaborating Clinics/American College of Rheumatology Damage Index (pedSDI) has been developed to analyze the disease damage. The domain of growth failure was included to the modified SDI as a damage measure for jSLE, in 2006.6,7

In 2007, Hiraki et al. ${ }^{8}$ suggested final height as evaluation of damage in jSLE since children with SLE may experience catch-up when the disease is accordingly managed, and the dose of corticosteroid is tailored appropriately.

Juvenile SLE patients may also experience delayed-onset puberty, particularly in late-onset childhood disease. Although life expectancy has improved in jSLE patients, the frequency of great morbidity may affect their health-span. Growth failure and delayed puberty may have an impact on the quality of life in jSLE patients. This information highlights the need for measuring organ damage of patients regularly and designing new treatment approaches for which the clinicians aim both managing the disease activity and alleviating irreversible damage.
It is well-known that growth of patients with chronic diseases such as jSLE may be affected by both the disease itself and the prescribed medications, particularly prolonged corticosteroid administration. ${ }^{6,7}$ Due to the rarity SLE in children, knowledge on growth in those patients is limited. Therefore, in this study, we aimed to investigate the growth parameters in Turkish children with SLE and to compare these growth parameters according to the presence or absence of cyclophosphamide, rituximab treatment, cumulative corticosteroid dose, proliferative nephritis and the last visit disease activity and damage index.

\section{PATIENTS AND METHODS}

This retrospective study was conducted at Çukurova University School of Medicine between June 2018 and December 2018. Medical files of a total of 65 jSLE patients were evaluated. Inclusion criteria were jSLE patients diagnosed according to the revised 1997 classification criteria of American College of Rheumatology ${ }^{9}$, followed-up for at least six months between January 2005 and June 2018, and whose anthropometric data were available at baseline and follow-up assessments. Some patients were excluded due to lack of clinical, laboratory, and medication data or growth parameters of patients and parents. The flow diagram of the study was given in Figure 1. Forty-five jSLE patients (5 males, 40 females;

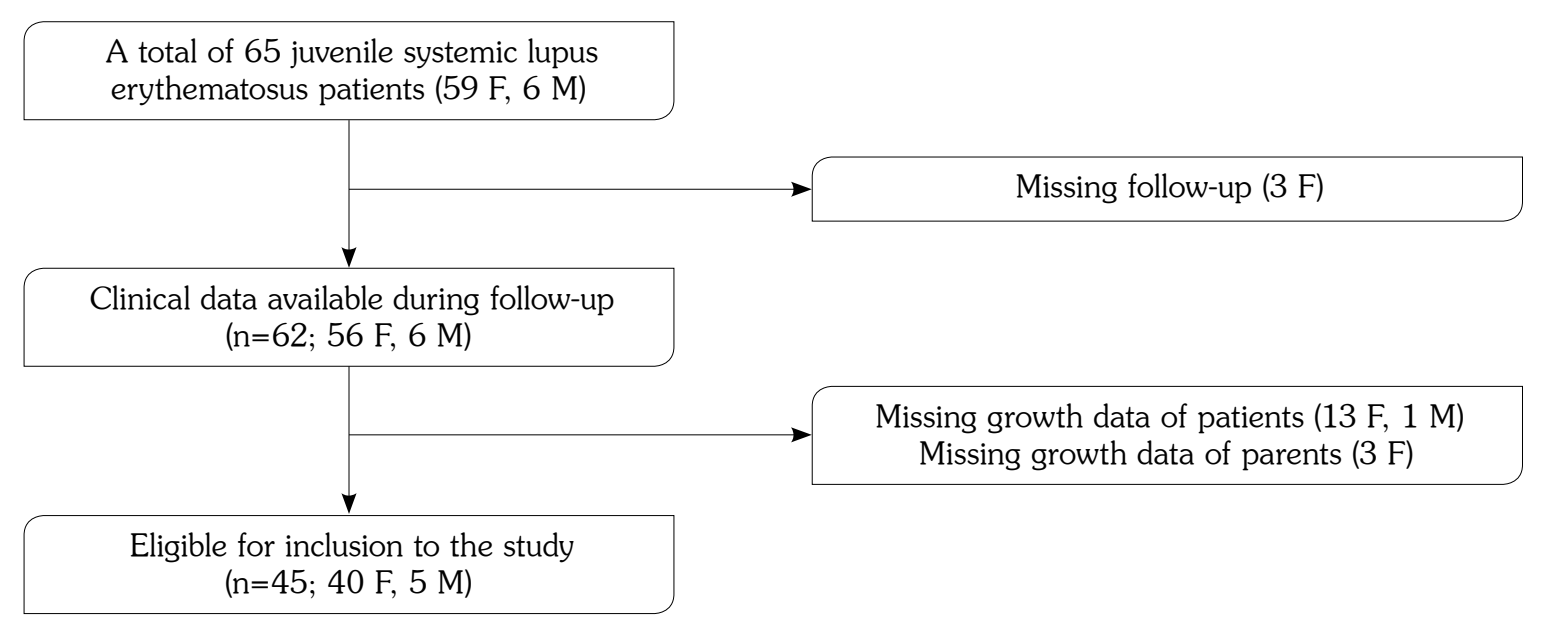

Figure 1. Flow diagram of juvenile systemic lupus erythematosus patients. F: Female; M: Males; n: Number. 
mean age $12.3 \pm 3.2$ years; range 7.1 to 18 years) were finally included. All patients were of Turkish descent. Medical files were retrospectively reviewed for data including sex, age at both disease onset and diagnosis, clinical characteristics, and medication data. Laboratory parameters including C-reactive protein, erythrocyte sedimentation rate, complement levels, and autoantibodies were also noted. The SLE Disease Activity Index 2000 (SLEDAI-2K) was calculated to measure disease activity at last visit. ${ }^{10}$ The disease outcome was assessed by utilizing PedSDI at last visit. ${ }^{7}$ The study protocol was approved by the Çukurova University School of Medicine Ethics Committee (approval number: 82/32). A written informed consent was obtained from legal guardians of each patient. The study was conducted in accordance with the principles of the Declaration of Helsinki.

Height $(\mathrm{cm})$ and weight $(\mathrm{kg})$ were preferentially measured in the morning at each visit by the same operator with the same type of stadiometer (Harpenden Stadiometer, Holtain Limited, Crosswell, UK) throughout the study. Parents' heights were also measured by the same operator and with the same type of stadiometer. Body mass index (BMI) was calculated as weight $(\mathrm{kg})$ divided by height (meters) squared. After the growth parameters including weight $(\mathrm{kg})$, height $(\mathrm{cm})$, and BMI were collected, $\mathrm{z}$-scores were calculated by anthropometric references in Turkish children. ${ }^{11}$ Parent-adjusted height $\mathrm{z}$-scores were also calculated as the difference between height z-score for chronological age and target height.

\section{Statistical analysis}

All statistical analysis was undertaken using the IBM SPSS version 20.0 software (IBM Corp., Armonk, NY, USA). Continuous variables were summarized as mean, standard deviation and as median, minimum-maximum where appropriate and categorical variables were given as percentages. The normality of distribution for growth indices was confirmed with the Kolmogorov-Smirnov test, stem-and-leaf diagram, and the histogram. The Student's t-test was used for comparison of continuous variables between two groups. Moreover, a paired sample t-test was utilized for comparing two dependent variables in the same study group. Height velocity standard deviation score was also evaluated by subtracting final height parameters from initial height parameters. Additionally, a Chi-square test was performed on data to designate whether the corticosteroid dose administered had any association on the last visit BMI. The statistical level of significance for all tests was determined to be 0.05 .

\section{RESULTS}

The median diagnostic delay was two months (range, 0-36 months). The general demographic features and clinical manifestations of jSLE patients were provided in Table 1. Of the $45 \mathrm{jSLE}$ patients, 23 (51.1\%) had proliferative nephritis. All patients were given methylprednisolone and hydroxychloroquine. Moreover, 19 (42.2\%) of them had pulse methylprednisolone (30 mg/kg/day) at the time of diagnosis. All patients were still on corticosteroid treatment at last visit. Furthermore, 28 (62.2\%) received cyclophosphamide and 17 (37.8\%) received rituximab treatment. The mean SLEDAI-2K score at diagnosis was $22.5 \pm 8.1$ and last median SLEDAI-2K score was 0 (range, 0-5). The number of patients with damage in at least one organ was $18(40 \%)$ and the median pedSDI score was 0 (range, 0-5). PedSDI scores were analyzed individually for all patients which revealed that growth failure was most commonly related to the damage $(\mathrm{n}=11,24.4 \%)$. Moreover, cataract was detected in four patients (8.9\%), nephrotic range proteinuria in three patients $(6.67 \%)$ and one patient $(2.2 \%)$ had scarring skin lesions on the face. One patient suffered from pericardiectomy, shrinking lung, pubertal delay, growth failure, and end-stage renal disease without dialysis requirement.

All patients' weight, height, BMI z-scores, and parent-adjusted height $z$-scores were analyzed at diagnosis and at last visit (Table 2). Two patients' (4.4\%) weight and height $z$-scores were below -2 at diagnosis. Regarding parent-adjusted height $\mathrm{z}$-scores, there were 17 patients (37.8\%) with scores below -1.5 at last visit.

The patients were grouped according to the age at disease onset as group 1 ( $\leq 11$ years) and group 2 (>11 years). Of the 45 patients, 27 (60\%) were diagnosed after 11 years of age. The last visit $\mathrm{z}$-scores were compared between the groups, which showed no statistically significant differences. 


\begin{tabular}{|c|c|c|c|c|c|}
\hline & $\mathrm{n}$ & $\%$ & Mean \pm SD & Median & Range \\
\hline \multicolumn{6}{|l|}{ Demographic characteristics } \\
\hline $\begin{array}{l}\text { Sex } \\
\text { Female } \\
\text { Male }\end{array}$ & $\begin{array}{c}40 \\
5\end{array}$ & $\begin{array}{l}88.9 \\
11.1\end{array}$ & & & \\
\hline Age at symptom onset (year) & & & $11.9 \pm 3.0$ & & \\
\hline Age at diagnosis & & & $12.3 \pm 3.2$ & & \\
\hline Diagnostic delay & & & & 2 & $0-36$ \\
\hline Disease duration & & & & 3.21 & $0.63-9.48$ \\
\hline Mean last visit SLEDAI-2K & & & $1.2 \pm 1.5$ & & \\
\hline \multicolumn{6}{|l|}{ Clinical characteristics } \\
\hline Constitutional symptoms & 43 & 95.6 & & & \\
\hline Raynaud phenomenon & 11 & 24.4 & & & \\
\hline Malar rash & 38 & 84.4 & & & \\
\hline Photosensitivity & 39 & 86.7 & & & \\
\hline Oral aphthosis & 24 & 53.3 & & & \\
\hline Vasculitis on the skin & 2 & 4.4 & & & \\
\hline Musculoskeletal involvement & 29 & 64.4 & & & \\
\hline Renal involvement & 35 & 77.8 & & & \\
\hline Neuropsychiatric involvement & 10 & 22.2 & & & \\
\hline Serositis & 6 & 13.6 & & & \\
\hline Hematological involvement & 32 & 71.1 & & & \\
\hline
\end{tabular}

The patients were further divided according to the diagnostic delay as group 1 (>3 months) and group 2 ( $\leq 3$ months). The last visit growth parameters were compared between the groups, which revealed no significant differences.

The last visit weight, height, BMI z-scores and parent-adjusted height $z$-scores of jSLE patients were compared according to having proliferative nephritis. There were no statistical differences in the parameters of the groups.
Furthermore, patients were grouped in terms of prescribed treatments. There were no statistically significant differences in last visit $z$-scores of patients who received cyclophosphamide and rituximab. Comparison of last visit growth parameters according to the presence or absence of cyclophosphamide, rituximab treatment, and proliferative nephritis were given in Table 3.

The median duration of corticosteroid treatment was 3.2 years (range; 0.6-9.4 years).

Table 2. Comparison of initial and last visit growth parameters of juvenile systemic lupus erythematosus patients $(n=45)$

\begin{tabular}{lcccc}
\hline & Initial visit & & Last visit & \\
\cline { 2 - 2 } Growth parameters & Mean $\pm \mathrm{SD}$ & & Mean $\pm \mathrm{SD}$ & \\
\hline Weight z-score & $-0.27 \pm 1.18$ & & $-0.28 \pm 1.32$ & 0.98 \\
Height $z$-score & $0.04 \pm 1.48$ & & $-0.72 \pm 1.30$ & $\mathbf{0 . 0 0 1}$ \\
Body mass index z-score & $-0.30 \pm 1.21$ & & $0.27 \pm 1.27$ & $\mathbf{0 . 0 1}$ \\
Parent-adjusted height $z$-score & $-0.31 \pm 1.51$ & & $-1.03 \pm 1.32$ & $\mathbf{0 . 0 0 1}$ \\
\hline SD: Standard deviation; Paired t-test was utilized for data comparison. Significant p values $(<0.05)$ are presented \\
in bold.
\end{tabular}


Table 3. Comparison of last visit growth parameters of juvenile systemic lupus erythematosus patients according to presence or absence of cyclophosphamide, rituximab treatment, and proliferative nephritis

\begin{tabular}{|c|c|c|c|c|c|c|c|}
\hline & \multicolumn{6}{|c|}{ Proliferative nephritis } & \multirow[b]{3}{*}{$p$} \\
\hline & \multicolumn{3}{|c|}{ Absence } & \multicolumn{3}{|c|}{ Presence } & \\
\hline & $\mathrm{n}$ & $\%$ & Mean \pm SD & $\mathrm{n}$ & $\%$ & Mean \pm SD & \\
\hline Growth parameters & 23 & 51.1 & & 22 & 48.9 & & \\
\hline Weight z-score & & & $-0.5 \pm 1.4$ & & & $-0.1 \pm 1.2$ & 0.32 \\
\hline Height z-score & & & $-0.7 \pm 1.5$ & & & $-0.8 \pm 1.1$ & 0.88 \\
\hline Body mass index z-score & & & $0.0 \pm 1.5$ & & & $0.5 \pm 1.0$ & 0.15 \\
\hline \multirow[t]{2}{*}{ Parent-adjusted height $z$-score } & & & $-1.0 \pm 1.4$ & & & $-1.1 \pm 1.3$ & 0.88 \\
\hline & \multicolumn{6}{|c|}{ Cyclophosphamide } & \\
\hline Growth parameters & 17 & 37.8 & & 28 & 62.2 & & \\
\hline Weight z-score & & & $-0.3 \pm 1.4$ & & & $-0.2 \pm 1.3$ & 0.83 \\
\hline Height z-score & & & $-0.5 \pm 1.5$ & & & $-0.8 \pm 1.2$ & 0.48 \\
\hline Body mass index z-score & & & $0.0 \pm 1.6$ & & & $0.4 \pm 1.0$ & 0.34 \\
\hline \multirow[t]{2}{*}{ Parent-adjusted height $z$-score } & & & $-0.8 \pm 1.4$ & & & $-1.2 \pm 1.2$ & 0.36 \\
\hline & \multicolumn{6}{|c|}{ Rituximab } & \\
\hline Growth parameters & 28 & 62.2 & & 17 & 37.8 & & \\
\hline Weight z-score & & & $-0.3 \pm 1.2$ & & & $-0.3 \pm 1.5$ & 0.93 \\
\hline Height z-score & & & $-0.6 \pm 1.3$ & & & $-1.0 \pm 1.3$ & 0.32 \\
\hline Body mass index z-score & & & $0.1 \pm 1.4$ & & & $0.5 \pm 1.1$ & 0.39 \\
\hline Parent-adjusted height $z$-score & & & $-1.0 \pm 1.3$ & & & $-1.1 \pm 1.4$ & 0.88 \\
\hline
\end{tabular}

The median cumulative corticosteroid dose was $13.9 \mathrm{~g}$ (range, 1.9-58 g) of methylprednisolone. We compared the last visit growth parameters according to cumulative corticosteroid dose: group $1<10 \mathrm{~g}$ and group $2 \geq 10 \mathrm{~g}$ of methylprednisolone. Although mean weight and BMI $\mathrm{z}$-scores were similar, the last visit mean height $\mathrm{z}$-score was significantly lower in group 2 $(p=0.003)$. However, last visit parent-adjusted height $z$-score was not significantly different between the groups. The comparison of last visit growth parameters according to cumulative corticosteroid dose was given in Table 4. The mean BMI score at last visit was $21.5 \pm 4.0$, while the frequency of overweight (BMI score $\geq 25$ ) patients was $6.7 \%(\mathrm{n}=3)$.

Moreover, patients were grouped according to the last visit SLEDAI-2K scores as group $1(0)$ and group $2(\geq 1)$. There were no statistically significant differences in last visit growth parameters between the two groups.

Table 4. Comparison of last visit growth parameters of juvenile systemic lupus erythematosus patients according to cumulative corticosteroid (methylprednisolone) dose

\begin{tabular}{lcccc}
\hline & $<10 \mathrm{gr}$ & & $\geq 10 \mathrm{gr}$ & \\
\cline { 2 - 2 } Growth parameters & Mean $\pm \mathrm{SD}$ & & Mean $\pm \mathrm{SD}$ & \\
\hline Weight z-score & $0.06 \pm 1.33$ & & $-0.42 \pm 1.27$ & 0.29 \\
Height z-score & $0.53 \pm 0.83$ & & $-1.00 \pm 1.33$ & $\mathbf{0 . 0 0 3}$ \\
Body mass index z-score & $0.12 \pm 1.70$ & & $0.32 \pm 1.11$ & 0.63 \\
Parent-adjusted height z-score & $-0.61 \pm 1.10$ & & $-1.18 \pm 1.37$ & 0.20 \\
\hline SD: Standard deviation; Student's t-test was used for data comparison. Significant p values (<0.05) are presented \\
in bold.
\end{tabular}


Table 5. Comparison of last visit growth parameters of juvenile systemic lupus erythematosus patients according to last visit disease activity and damage index

\begin{tabular}{|c|c|c|c|c|c|c|c|}
\hline & \multicolumn{6}{|c|}{ pedSDI } & \multirow[b]{3}{*}{$p$} \\
\hline & \multicolumn{3}{|c|}{0} & \multicolumn{3}{|c|}{$\geq 1$} & \\
\hline & $\mathrm{n}$ & $\%$ & Mean \pm SD & $\mathrm{n}$ & $\%$ & Mean \pm SD & \\
\hline Growth parameters & 27 & 60 & & 18 & 40 & & \\
\hline Weight z-score & & & $-0.05 \pm 1.064$ & & & $-0.61 \pm 1.62$ & 0.16 \\
\hline Height z-score & & & $-0.111 \pm 0.88$ & & & $-1.63 \pm 1.30$ & 0.001 \\
\hline Body mass index $z$-score & & & $0.12 \pm 1.26$ & & & $0.49 \pm 1.30$ & 0.34 \\
\hline \multirow[t]{2}{*}{ Parent-adjusted height z-score } & & & $-0.51 \pm 1.13$ & & & $-1.81 \pm 1.20$ & 0.001 \\
\hline & \multicolumn{6}{|c|}{ SLEDAI-2K } & \\
\hline Growth parameters & 25 & 55.6 & & 20 & 44.4 & & \\
\hline Weight z-score & & & $-0.11 \pm 1.30$ & & & $-0.49 \pm 1.35$ & 0.34 \\
\hline Height z-score & & & $-0.52 \pm 1.39$ & & & $-0.96 \pm 1.16$ & 0.28 \\
\hline Body mass index $z$-score & & & $0.32 \pm 1.34$ & & & $0.21 \pm 1.21$ & 0.76 \\
\hline Parent-adjusted height $z$-score & & & $-0.85 \pm 1.50$ & & & $-1.2 \pm 1.03$ & 0.31 \\
\hline
\end{tabular}

Additionally, patients were also grouped according to the last visit pedSDI scores as group $1(0, n=27)$ and group $2(\geq 1, n=18)$. There was no statistical significance between the groups in terms of last visit growth parameters. Comparison of last visit growth parameters according to the last visit SLEDAI-2K scores and pedSDI was given in Table 5 .

\section{DISCUSSION}

In the present study, initial and last visit growth parameters of jSLE patients were compared. Mean height $\mathrm{z}$-score and mean parent-adjusted height $z$-score of jSLE patients were significantly lower at last visit. Growth parameters of jSLE patients were also compared according to the presence or absence of cyclophosphamide, rituximab treatment, an upwards of $10 \mathrm{~g}$ cumulative corticosteroid dose, and proliferative nephritis. Initial and last visit growth parameters did not differ in terms of having proliferative nephritis and immunosuppressive treatment, including cyclophosphamide and rituximab. Although the last visit mean height $z$-score of jSLE patients having $\geq 10$ g cumulative corticosteroid was significantly lower than those having $<10 \mathrm{~g}$, the difference was not significant between mean parent-adjusted height $z$-scores of patients according to the cumulative corticosteroid dose. In this study, the presence of damage was related to a lower last visit mean height $\mathrm{z}$-score. The patients with damage in at least one organ were potentially shorter. However, since the growth failure is an item of pedSDI damage index, it is not surprising that patients with a pedSDI score $\geq 1$ were found to have lower mean height $z$-score. Therefore, we could not conclude on the relationship of pedSDI scores with growth parameters.

Knowledge about growth, final height, and pubertal development in jSLE is limited because of the scarcity of the disease and relevant cohort studies. To date, various studies have reported on the clinical and laboratory manifestations of jSLE patients worldwide. However, only a few studies have provided the frequency of growth failure, which was reported to be between $5.1-32 \%$ worldwide. ${ }^{12-15}$

The first prospective report evaluating the growth and puberty in jSLE patients was held by the Paediatric Rheumatology International Trials Organisation in 2011. ${ }^{16}$ They assessed 557 jSLE patients for 26 months of whom 331 (females, $\mathrm{n}=276,83.4 \%$ ) had complete height data and 274 also had both parents' heights accessible. Growth failure was observed in 16.9\% of females and $22.4 \%$ of males at the beginning 
of the study. During the follow-up, a statistically significant reduction was observed in actual and parent-adjusted height $z$-scores of patients. Female patients were grouped according to age at disease onset. Prepubertal females with the age onset below eight years were observed to have significantly lower parent-adjusted height $z$-scores. At the end of the study, growth failure and height reduction were more frequently observed in females with disease onset age below 12 years than females aged at least 12 years. Although the same pattern was observed in males with onset age below 14 years, this difference was not statistically significant. Thus, it was presumed that age at disease onset might be an independent risk factor for height deflection and growth failure in females with jSLE. Ultimately, the proportion of growth failure was reported in $14.7 \%$ of the females and $24.5 \%$ of the males. The determinants of growth failure were found to be growth failure at first assessment, cumulative corticosteroid dose, and age at first visit. In the study, median BMI $\mathrm{z}$-score reached the peak number at six months and was still significantly above baseline after 26 months, which was explained by higher doses of corticosteroid used at baseline to control the disease activity. ${ }^{16}$ Besides growth parameters, the pubertal development of jSLE patients was also assessed in the study. While delayed pubertal onset was observed in $15.3 \%$ of the females and $24 \%$ of the males, some degree of delayed pubertal development was observed in $36.1 \%$ of the females and $44 \%$ of the males. It was concluded that prepubertal and peripubertal children treated with at least $400 \mathrm{mg} / \mathrm{kg}$ cumulative dose of corticosteroid are those at risk of having a negative effect on height and pubertal development. ${ }^{16}$ Similar to the previous study, in the present study, mean height $\mathrm{z}$-score and parent-adjusted height $\mathrm{z}$-score were significantly lower at last visit. However, the difference in growth parameters between sexes was not investigated due to the small number of male patients in the present study. Moreover, jSLE patients were not evaluated for the pubertal characteristics; therefore, the pubertal maturation of the patients in the present study is unknown. As physicians, while we focus on treating such difficult diseases, we may forget about patients' psychological and developmental status. However, these are the cornerstones of well-being, particularly in adolescent children.
Furthermore, Abdalla et al. ${ }^{15}$ have reported a study which included 25 jSLE patients and have observed growth failure in eight (32\%) patients. The factors that related to the growth failure in that study were having growth failure at the time of diagnosis and a higher cumulative corticosteroid dose. Although disease duration tended to be longer among the growth failure group, the difference was not statistically significant. They have not found any significant difference between the disease severity at the time of diagnosis and growth failure. However, they have not given any information about the pedSDI scores of patients. In the present study, the growth parameters of patients who received corticosteroid (methylprednisolone) dose of at least $10 \mathrm{~g} \mathrm{had}$ lower mean height $z$-score, though parent-adjusted height $z$-score did not significantly differ regarding commenced cumulative corticosteroid dose.

In addition, Heshin-Bekenstein et al. ${ }^{17}$ have recently revealed the final heights of 72 jSLE patients who entered into adulthood. In that study, patients' heights were $2.4 \mathrm{~cm}$ shorter than their target heights. Besides, female patients, who were diagnosed between 11-13 years, had the highest risk for diminished final height. They have also concluded that utilizing cyclophosphamide may be a significant risk factor for diminished final height. In contrast to these findings, in the present study, no impact has been detected of cyclophosphamide usage and the age at disease onset on growth parameters.

In 2013, Manaboriboon et al. ${ }^{18}$ investigated the weight change over time in jSLE patients and the relationships with corticosteroid. In the study, at the beginning of corticosteroid treatment, $90 \%$ of jSLE patients had normal BMI. However, at the end of the therapy, nearly 20\% of the patients had BMI $\geq 25$, of which $10 \%$ were obese. In that study, the highest risk factors for developing obesity were high BMI at diagnosis and cumulative corticosteroid dose. However, they did not find any effect of the duration of corticosteroid therapy on obesity. Consequently, they have proposed that physicians should be focused on obesity-preventive strategies besides dietary advice, particularly for those with high $\mathrm{BMI}$ at the initiation of treatment. In the present study, the frequency of overweight patients was lower than in the previous study. 
Moreover, in the present study, while 24.4\% of the patients had short stature according to the reference anthropometric values, calculation of parent-adjusted height $\mathrm{z}$-scores identified short stature in $37.8 \%$ of the patients. This difference has led us to think that in clinical practice, adjusting height with the heights of the parents would prevent the underestimation of short stature in children with chronic diseases. However, while mean height $z$-score was significantly lower in patients treated with a cumulative corticosteroid dose of at least $10 \mathrm{~g}$ before the parental adjustment, final parent-adjusted height $\mathrm{z}$-scores did not differ between patients regarding the cumulative corticosteroid dose.

Despite the limitations of this study including the small sample size and the retrospective design, findings of the present study may be considered valuable due to the rarity of SLE among children and the limited data reported on growth parameters of jSLE patients in the literature. Moreover, calculation of the parentaladjusted height $z$-scores has also made this study stronger. Nevertheless, further studies evaluating sexual maturation and socioeconomic status of jSLE patients in addition to growth parameters would add more valuable data to the literature.

In conclusion, in the present study, mean height $\mathrm{z}$-score and parent-adjusted height $\mathrm{z}$-score of jSLE patients were significantly lower at last visit. At least $10 \mathrm{~g}$ of cumulative corticosteroid dose was significantly related to the lower last visit mean height $z$-score. Age at disease onset, diagnostic delay, cyclophosphamide and rituximab treatment, and disease activity did not affect the last visit growth parameters. Because of the small number of jSLE patients included in this study, there is still an unmet need for multicenter and long-term prospective studies evaluating the growth parameters of children with SLE.

\section{Declaration of conflicting interests}

The authors declared no conflicts of interest with respect to the authorship and/or publication of this article.

\section{Funding}

The authors received no financial support for the research and/or authorship of this article.

\section{REFERENCES}

1. Klein-Gitelman M, Lane JC. Systemic lupus erythematosus. In: Petty R, Laxer R, Lindsley C, Wedderburn L, editors. Textbook of Pediatric Rheumatology. 7th ed. Philadelphia: Saunders; 2010. p. 285-317.

2. Hiraki LT, Benseler SM, Tyrrell PN, Harvey E, Hebert D, Silverman ED. Ethnic differences in pediatric systemic lupus erythematosus. J Rheumatol 2009;36:2539-46.

3. Balci S, Ekinci RMK, Bayazit AK, Melek E, Dogruel $\mathrm{D}$, Altintas DU, et al. Juvenile systemic lupus erythematosus: a single-center experience from southern Turkey. Clin Rheumatol 2019;38:1459-68.

4. Hersh AO, Trupin L, Yazdany J, Panopalis P, Julian L, Katz $P$, et al. Childhood-onset disease as a predictor of mortality in an adult cohort of patients with systemic lupus erythematosus. Arthritis Care Res (Hoboken) 2010;62:1152-9.

5. Ravelli A, Ruperto N, Martini A. Outcome in juvenile onset systemic lupus erythematosus. Curr Opin Rheumatol 2005;17:568-73.

6. Bandeira M, Buratti S, Bartoli M, Gasparini C, Breda $\mathrm{L}$, Pistorio $\mathrm{A}$, et al. Relationship between damage accrual, disease flares and cumulative drug therapies in juvenile-onset systemic lupus erythematosus. Lupus 2006;15:515-20.

7. Gutiérrez-Suárez R, Ruperto N, Gastaldi R, Pistorio A, Felici E, Burgos-Vargas R, et al. A proposal for a pediatric version of the Systemic Lupus International Collaborating Clinics/American College of Rheumatology Damage Index based on the analysis of 1,015 patients with juvenile-onset systemic lupus erythematosus. Arthritis Rheum 2006;54:2989-96.

8. Hiraki LT, Hamilton J, Silverman ED. Measuring permanent damage in pediatric systemic lupus erythematosus. Lupus 2007;16:657-62.

9. Hochberg MC. Updating the American College of Rheumatology revised criteria for the classification of systemic lupus erythematosus. Arthritis Rheum 1997;40:1725.

10. Gladman DD, Ibañez D, Urowitz MB. Systemic lupus erythematosus disease activity index 2000. J Rheumatol 2002;29:288-91.

11. Neyzi O, Günöz H, Furman A, Bundak R, Gökçay G, Darendeliler $\mathrm{F}$, et al. Türk çocuklarında vücut ağırlığı, boy uzunluğu, baş çevresi ve vücut kitle indeksi referans değerleri. Çocuk Sağlığ ve Hastalıkları Dergisi 2008;51:1-14.

12. Sahin S, Adrovic A, Barut K, Canpolat N, Ozluk Y, Kilicaslan I, et al. Juvenile systemic lupus erythematosus in Turkey: demographic, clinical and laboratory features with disease activity and outcome. Lupus 2018;27:514-9.

13. Gulay CB, Dans LF. Clinical presentations and outcomes of Filipino juvenile systemic lupus erythematosus. Pediatr Rheumatol Online J 2011;9:7. 
14. Salah S, Lotfy HM, Mokbel AN, Kaddah AM, Fahmy N. Damage index in childhood-onset systemic lupus erythematosus in Egypt. Pediatr Rheumatol Online J 2011;9:36.

15. Abdalla E, Jeyaseelan L, Ullah I, Abdwani R. Growth Pattern in Children with Systemic Lupus Erythematosus. Oman Med J 2017;32:284-90.

16. Rygg M, Pistorio A, Ravelli A, Maghnie M, Di Iorgi N, Bader-Meunier B, et al. A longitudinal PRINTO study on growth and puberty in juvenile systemic lupus erythematosus. Ann Rheum Dis 2012;71:511-7.

17. Heshin-Bekenstein M, Perl L, Hersh AO, von Scheven E, Yelin E, Trupin L, et al. Final adult height of patients with childhood-onset systemic lupus erythematosus: a cross sectional analysis. Pediatr Rheumatol Online J 2018;16:30.

18. Manaboriboon B, Silverman ED, Homsanit M, Chui $\mathrm{H}$, Kaufman M. Weight change associated with corticosteroid therapy in adolescents with systemic lupus erythematosus. Lupus 2013;22:164-70. 